\title{
Objects Removed for Study
}

\author{
Rafael Guendelman Hales
}

- ABSTRACT: "Objects Removed for Study" is a creative remaking of a fraction of the Library of Ashurbanipal (part of the Assyrian collection of the British Museum) by a group of women from the Iraqi Community Association in London. Inspired by the main role of the library as a guide for the Assyrian king Ashurbanipal, and considering the current situation in Iraq, the women were invited to rewrite and re-create a series of ceramic books and artifacts. This project aims to critically rethink both the identity and the role of these old artifacts in the articulation of new sensitivities and possibilities in today's context of displacement.

KEYWORDS: antagonism, critical spatial practice, displacements, encounters, Iraq, narratives, participation

\section{Context: Displaced and Displayed}

The Royal Library in Mosul, Iraq, is the oldest surviving library in the world and was built around $600 \mathrm{BC}$ by the Neo-Assyrian king Ashurbanipal. It comprises a collection of clay tablets and fragments containing different types of texts, which can, in some cases, be called books. The majority of these tablets and fragments consists of omens, astrological interpretations, and mystical conceptions that guided Ashurbanipal in leading his empire. ${ }^{1}$ The library was "discovered" between the years 1849 and 1851 by the excavator Austen Henry Layard in Nineveh, present-day Mosul, Iraq. It was then appropriated by Britain and transferred to the British Museum in London. In spite of long-standing claims for the repatriation of such artifacts to their place of origin, the lack of political will on the British side means that these Iraqi requests have remained unaddressed.

The project "Objects Removed for Study" stems from questioning the current relevance of these pieces, and considering the patent ethical and political aspects of their remaining in Britain. The first point to consider in this context is how such objects can be rearticulated, beyond their status as historical artifacts, to help us think about the present. The second point concerns the preservation of these objects, as the responsibility of the British Museum, but also the hypothetical responsibility of the Iraqi people. To reflect on these issues, I contacted the Iraqi Community Association in London to look into the possibility of rethinking the library from within the community.

The Iraqi Community Association is a 50-year-old organization that has served as a space for gathering since its foundation. It provides legal counsel to the community, creates a network of communication among its members, and acts as an important meeting center for different activities related to culture, politics, and expatriate Iraqi society in general. There are two main 
groups that meet regularly: the Older People's Group and the Women's Group. Even though I became involved with both groups, it was the latter group that I established a deeper connection with and decided to collaborate with. Working exclusively with the Women's Group was not something I had foreseen initially; however, such a collaboration has given the project an extra layer of political depth because of the fact that the original library was created, organized, and authored by a male figure (King Ashurbanipal).

In the first stage, the main challenge was to gain the trust of the Women's Group and the community in general. Coming from Chile and with basic knowledge of the Arabic language, although with Palestinian roots, I was a stranger to the group. In this context, the association's support, and especially from two members, Rayya and Fawzia, was crucial throughout. At times, they acted as interpreters, which enabled me to appropriately share the ideas and concepts behind the project with the community, eventually attaining their blessing to develop it. They saw in the project an opportunity to develop a meaningful activity by and for the community.

\section{The Project: A Collective Rewriting}

The project was carried out in three stages. First, there was a stage of dialogue around the library and its heritage; second, the recreation stage, where a fraction of the library was re-created by the group with the incorporation of their own texts on each artifact; and third, the exhibition stage, where the new pieces were exhibited at the Iraqi Community Association.

During the first stage, I organized meetings within the community to introduce the main features of and expectations around the process. The project was not only about the pieces and the community, but also about myself in relation to them, in an exercise of complementary dialogue through which the project could be devised together. ${ }^{2}$ In this stage, we organized different activities: we visited the museum and the library itself, shared personal objects that allowed us to talk about our own history, and discussed the current political and social situation in Iraq (a crucial moment of restructuring in the aftermath of ongoing occupation and conflict). ${ }^{3}$ We also discussed the present and past situations of Chile, marked by its recent violent history of dictatorship, with thousands of families who were victims of state violence ${ }^{4}$ and whose dead are still missing; the perpetrators of these crimes have still not faced justice. To differing degrees, both Iraq and Chile have a recent past of political violence in common.

Regarding the library and its supposed centrality in people's imaginations, opinions were diverse. Not everyone in the group had visited it before our project, but they all shared a feeling of pride related to that piece of Iraqi heritage. In terms of the library being in Britain instead of Iraq, opinions were divided. Some of the women defended the fact that the library was "kept" in the British Museum, arguing that in Iraq it would have been destroyed, while others thought that the library should be in Mosul, as it belongs to its people. The discussion was open, and the topic eventually shifted from the library and the artifacts to their own identity, starting with the country that expelled them (Iraq) and the one that, despite invading and occupying their land (Britain), has "welcomed" or at least "hosted" them.

During the second stage, we discussed the nature and content of the new ceramics that would be produced. The main topic of concern that arose throughout was the past and present of Iraq: more specifically, its idealized past (both of ancient Iraq and their own past in the country before leaving) and today's uncertain situation. My suggestion was to create these pieces with the same intention underpinning the creation of the originals: that is, as artifacts that helped Ashurbanipal in his decisions, but in the context of present-day Iraq. Hence the exercise was to produce new artifacts that could help a contemporary Ashurbanipal guide his people. 
I was personally interested in the role that the original artifacts could serve in creating a dialogue between the present and the past on a material level, not only through words, but by devising a past "that still influences us and that is still active . . . not to yet become history" (Ebeling 2017: 66). In this case, the process is multilayered: the past of the Assyrian culture, the past of extraction, the past of each participant related to Iraq, and also other potential pasts, all of them connected with the now.

Each participant created at least one piece of the Ashurbanipal Library in a scale of $1: 1$. In this stage, I informed the participants about how to work with ceramics. After selecting the pieces that would be replicated, we decided what would be written onto each one of them. The content of the pieces was diverse and stemmed from the participants' personal experiences. There were political, poetic, pragmatic, hopeful, and hopeless texts. The project, conceived in part as a participatory art project, tried to create an open exploration of the main concerns of the members of the group, without banning or encouraging any opinions. This was done considering the importance of allowing emerging dialogue in this type of projects, without forcing the experience into any political, rational, or moral frame (Bishop 2012: 18).

Finally, in the last stage, the 24 pieces made in the workshops were exhibited at the Iraqi Community Association inside small display boxes that also served as containers of what could one day be used to send the piece to Iraq. Additionally, transcriptions and translations of the texts from Arabic to English were provided. On the exhibition day, each piece was read aloud by Fawzia, who also opened a dialogue with the audience, who were mostly members of the community and the women who had participated in the process. This new library is one step removed from the museum space. It is physically far by virtue of being a new space for the pieces, but it is also changing their axis of display-from a vertical one to a horizontal oneallowing for interaction between the pieces and the audience.

In its three different phases, the project explored, first, the ideas behind heritage and identity in the context of displacement, through conversations around our own history and the history of the library. Second, it framed the act of remaking the pieces, to rethink heritage and archaeological objects, as a zone of potentiality for the participants, to personally interact with the now through the objects. Third, the exhibition of the pieces at the Iraqi Community Association created a new axis of engagement between the community and the project, generating a new space of dialogue and discussion through the pieces, but also with the community at large.

Ultimately, it is through the collective making and remaking of these pieces that a space of dialogue has been reestablished with and within the Iraqi Community Association and its members' histories. Indeed, such a collaboration, in the form of re-creating objects that officially belong to the past, was in particular an attempt to revisit history in the present as a critical but above all as a transformative space of interaction with multiple reconfigurations and readings. 
Figures 1-9. Photographs by the author.
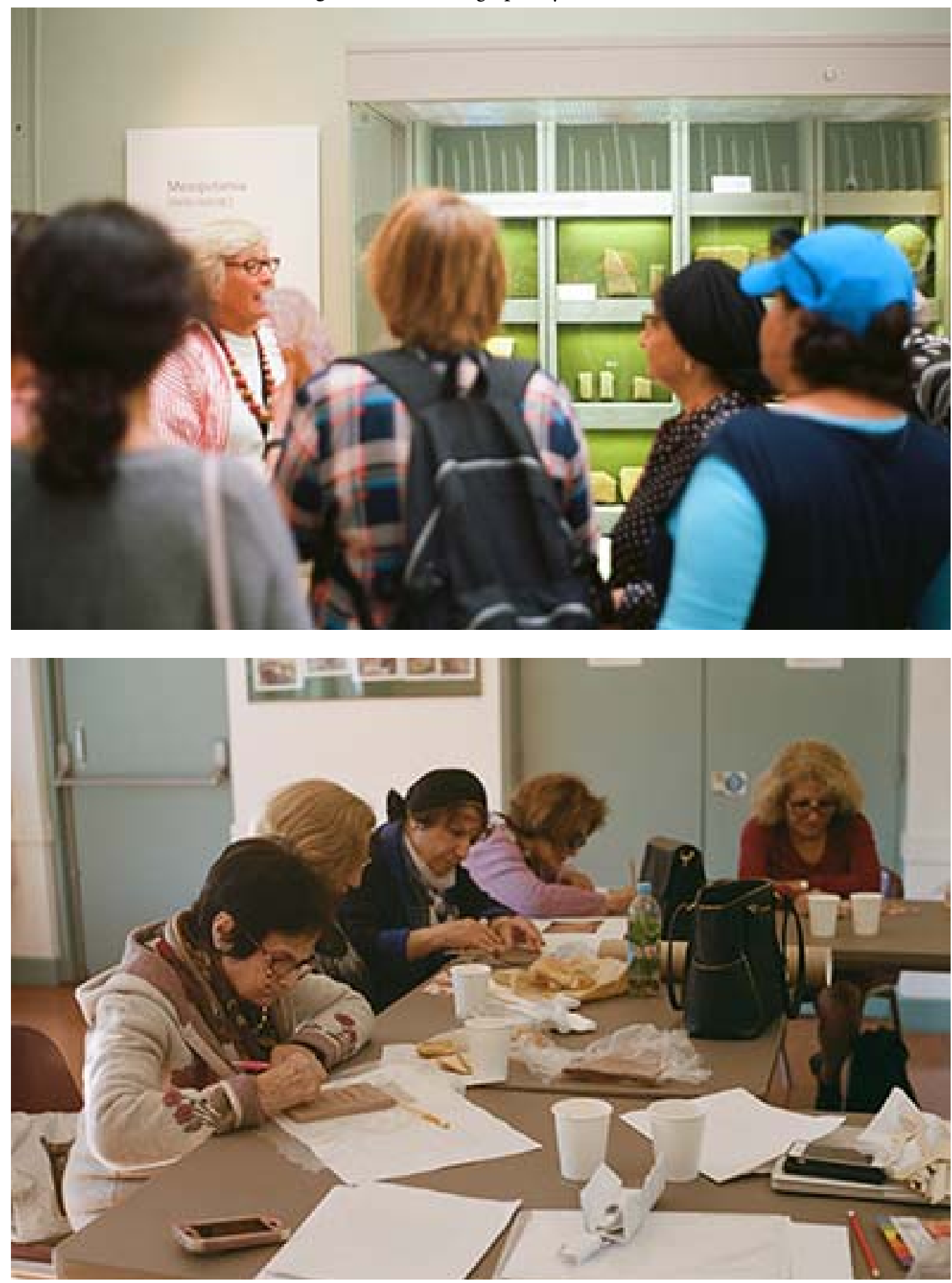

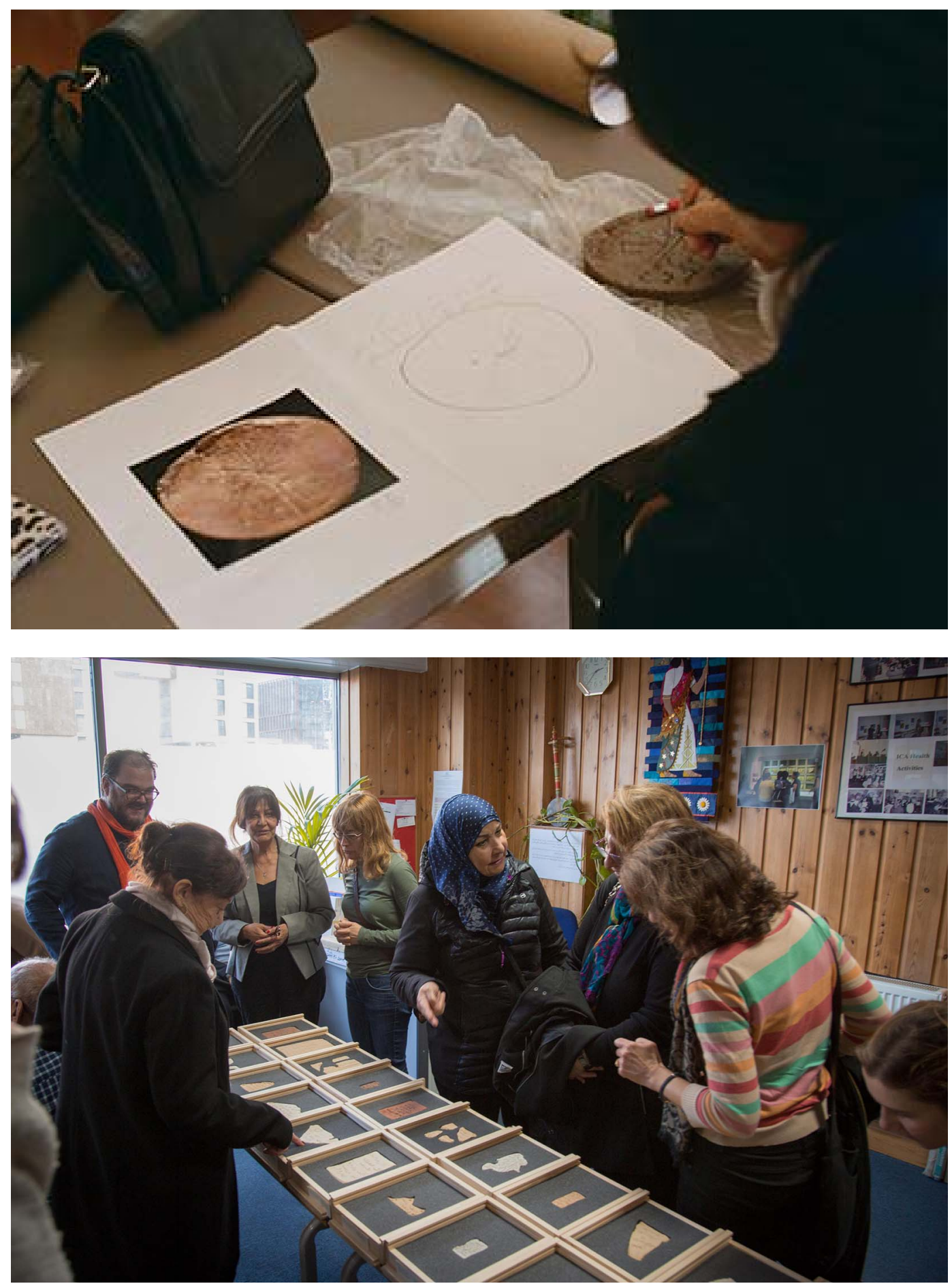
Objects Removed for Study 267

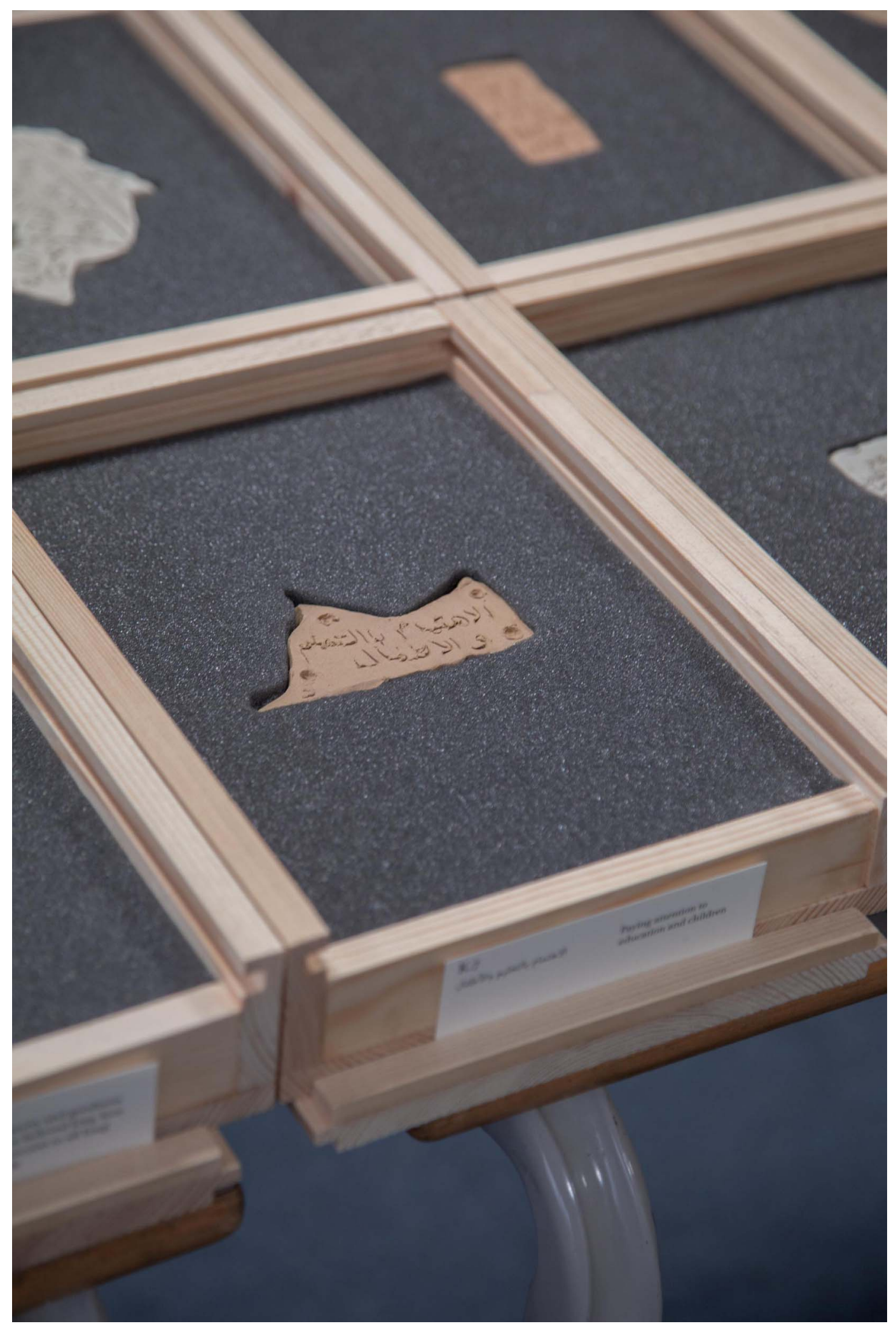




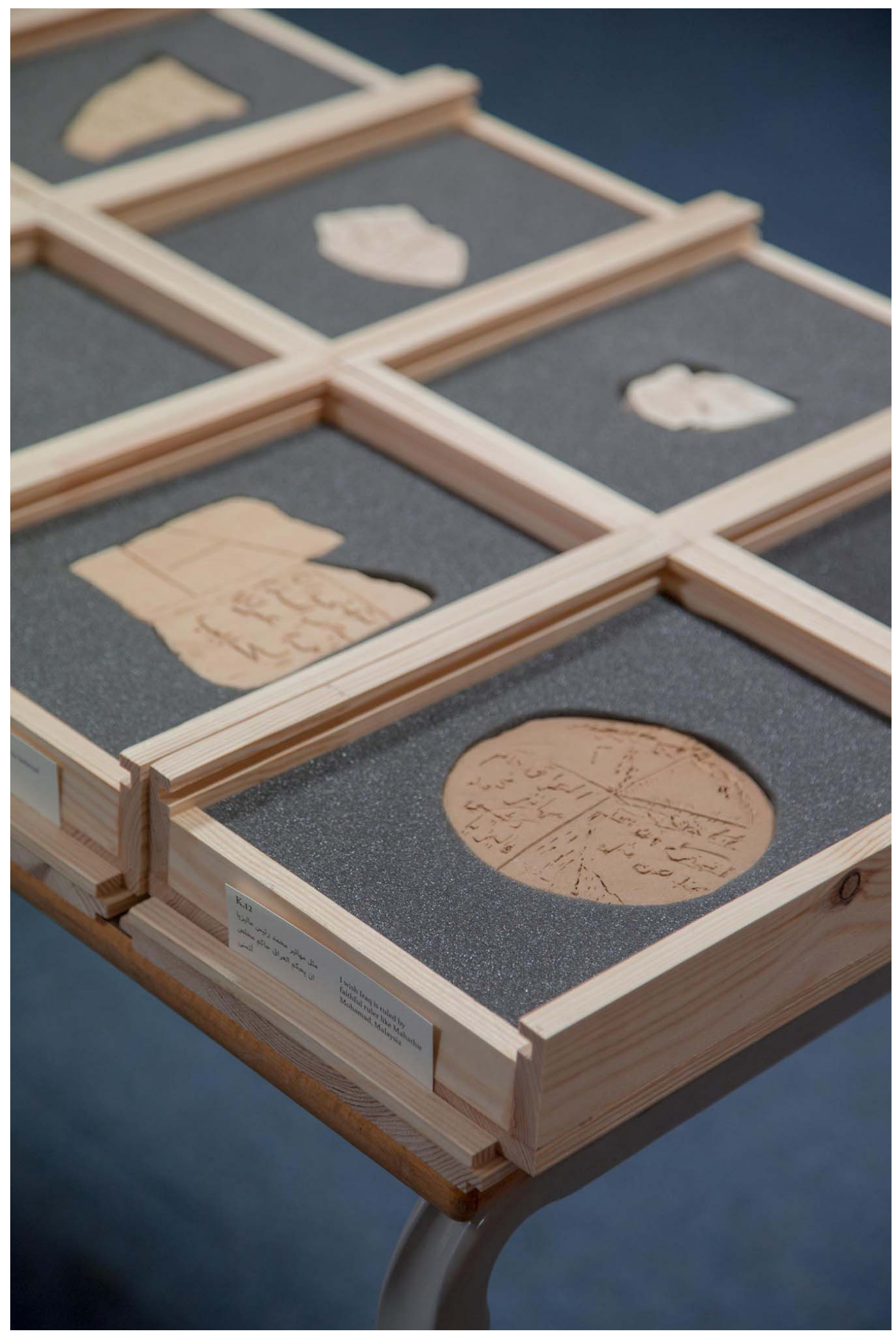



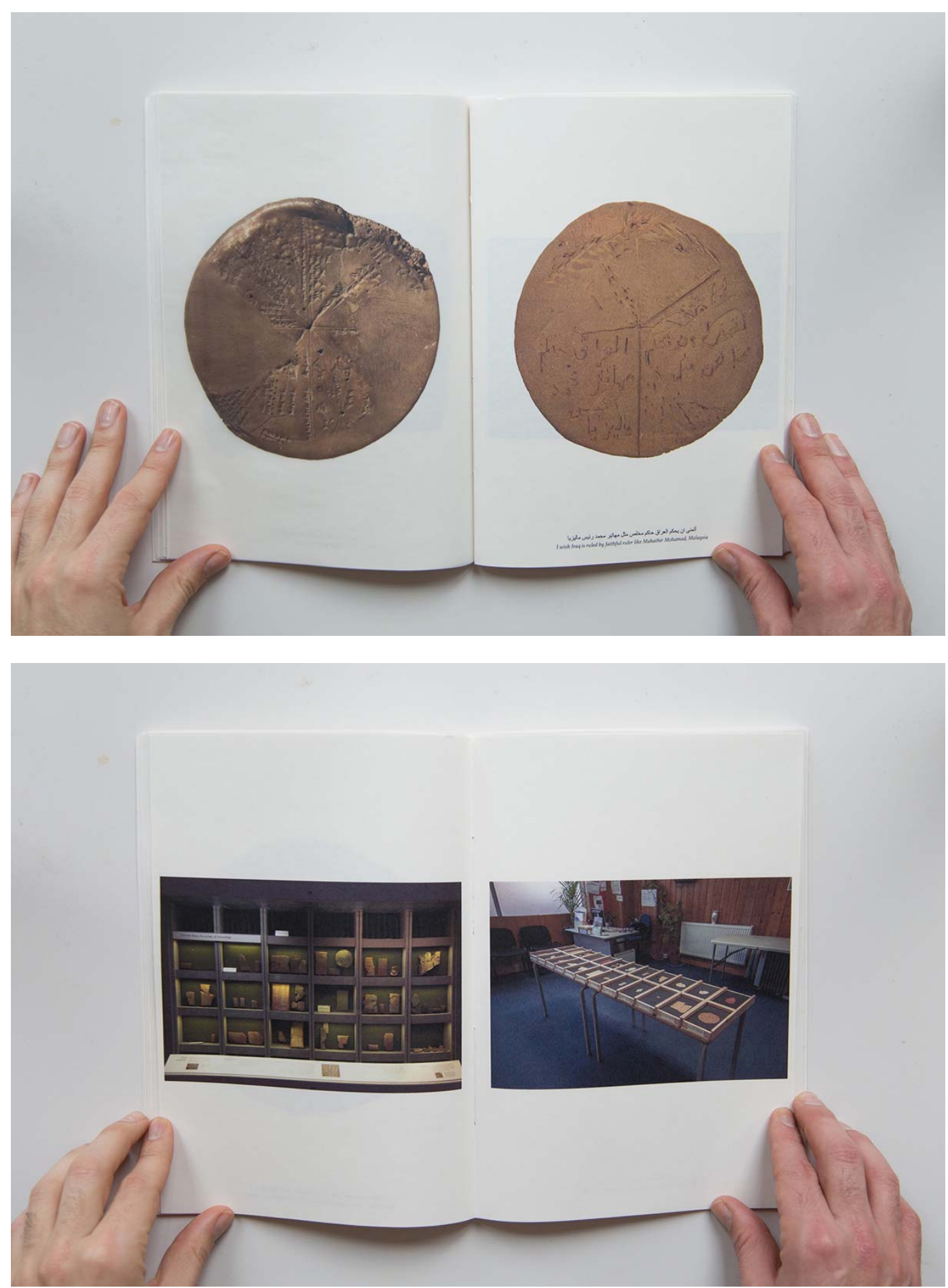


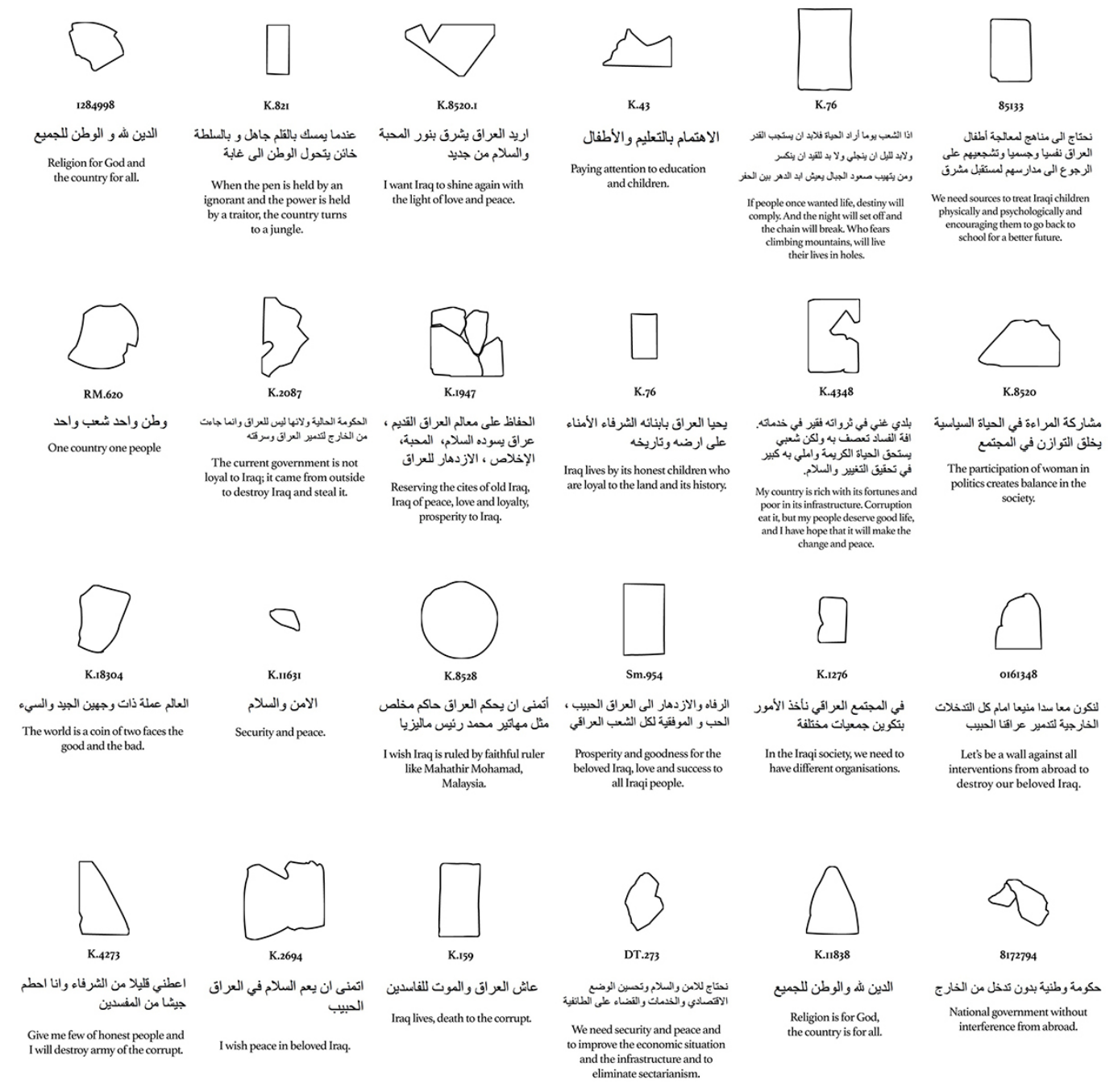


RAFAEL GUENDELMAN HALES is a visual artist from Chile whose work focuses on past and contemporary stories and the roles of place and space in constructing personal and collective identities. Rafael's projects have been supported by the National Art Funds of Chile (FONDART), the Art Funding of the Department of Foreign Affairs (DIRAC), and the National Scholarship for Master Studies (CONICYT). In addition to holding residencies at the Center for Art and Urbanistics of Berlin and at Laznia in Gdansk, Poland, his work has been exhibited widely, including at the Museo Nacional de Bellas Artes, Santiago; Museo de la Solidaridad Salvador Allende, Santiago; Parque Cultural de Valparaíso; Casa de las Américas, La Habana; Haus der Kulturen der Welt, Berlin; Palais de Tokyo, Paris; Al-Ma’al Lab, Jerusalem, and Khalil Sakakini Cultural Center, Bethlehem. His website is https:// rafaelguendelman.com/.

\section{NOTES}

1. Eleanor Robson, July 2018, personal interview.

2. Inspired by the Reunión project by artist Dani Zelko, where he explains the relation as unity and as such "is not one, is two. One in relation to another" (Zelko 2017).

3. When I started the project ISIS had just been defeated and the idea of a "new Iraq" was an important topic. It was also a very intense period of protests against public sector/service cuts from central government.

4. In my case, my mother was kidnapped, and my uncle disappeared and was presumably killed during the dictatorship.

\section{REFERENCES}

Bishop, Claire. 2012. Artificial Hells. New York: Verso.

Ebeling, Knut. 2017. There Is No Now: An Archeology of Contemporaneity. Berlin: Sternberg Press.

Zelko, Dani. 2017. Reunión. Mexico City: Editorial Gato Negro. 